\title{
Human Work Interaction Design of the Smart University
}

\author{
José Abdelnour-Nocera ${ }^{1}$, Samia Oussena ${ }^{1}$, Catherine Burns ${ }^{2}$ \\ ${ }^{1}$ University of West London, School of Computing and Technology \\ London, W5 5RF, England \\ \{jose.abdelnour-nocera, samia.oussena \}@uwl.ac.uk \\ ${ }^{2}$ University of Waterloo, Centre for Bioengineering and Biotechnologyt \\ 200 University Avenue West, Waterloo, N2L3G1, Canada \\ catherine.burns@uwaterloo.ca
}

\begin{abstract}
In this paper we present human work interaction design challenges and opportunities for the vision of the Smart University as a platform that provides foundational context data to deliver the university of the future. While learning analytics have enable access to digital footprints of student activities and progress in terms of data such as demographics, grades, recruitment and performance, they cannot provide information about activities and interaction in the physical study and work spaces in a university. The smart university proposes a novel platform that will provide context aware information to students through the integration of learning analytics with data sensed using cyberphysical devices in order to provide a holistic view of the environments that universities offer to students. However, designing the interaction of students and staff in the smart university ecology of information and sensing devices requires an understanding of how they work as individuals, as members of teams and communities. Through two use cases we illustrate how insights obtained from social cognitive work analysis can be used for the design guidelines of the different interfaces part of the smart university ecology.
\end{abstract}

Keywords: smart university, human work interaction design, cognitive work analysis, user interface design.

\section{Introduction}

The Smart University is a vision where the university, as a platform, provides foundational context data to deliver the university of the future. As higher education funding in Europe continues decreasing, universities are more reliant on income generated from students. Thus, understanding student progression and identifying ways to improve the students experience are vital to any institution. To improve their students' experience, universities are increasingly reliant on technology to improve and expand their services to students. In this paper we present our proposed version of the smart university and how human work interaction design (HWID) [1] can support the im-

adfa, p. 1, 2015.

(c) Springer-Verlag Berlin Heidelberg 2015 
plementation of this platform at design level. Although, as part of Smart university ecosystem, some applications have been already implemented [2,3], the discussions in the paper refers to a conceptual design of the Smart University platform.

Smart campus platforms have been researched and reported in the literature and some aspects have been also implemented in some universities. For example, Lei et al., [4] propose the design of a smart laboratory that measure, analyse and regulate the thermal comfort by use of cyber-physical devices. The University of Southern California implemented smart buildings management in the building. A more holistic vision has also been proposed; iCampus, as envisioned by $\mathrm{EBTIC}^{1}$, is an initiative that proposes the university of the 21st century be composed of six functional areas or pillars, designed to enrich students' experiences throughout their learning lifecycle: iLearning, iGovernance, iGreen, iHealth, iSocial, and iManagement. Although this is inline with our perspective, this initiative is still at the development stage and has a very broad scope. Our proposed platform is different in that our emphasis is on the design of the software platform that will allow the delivery of the vision. The implementation of the platform will take a data-oriented architecture approach. The focus is on how to develop a high-quality platform that will allow the use of cyber-physical devices and data analytics for the university of the future. Students' interactions with university systems are leaving an increasing amount of digital footprint which can be harnessed to understand behaviour and activities of students as well as help them become more effective in their studies and preparation of their career. Learning analytics have used these digital footprints left by students to gain insight on the students' progress and to build a personalised learning environment. However, most of Learning analytics projects have been looking at the monitoring of the digital environment that the institution offers to the students. Smart university vision is to provide a novel platform that will provide context aware information to students through the integration of learning analytics with data sensed using cyber-physical devices in order to provide a holistic view of the environments that universities offer to students. Additionally, this will augment the traditional learning analytics with data related to the physical environment and allow the investigation of these intelligent buildings and their effect on the learning processes.

Designing the interaction of students and staff in the smart university ecology of information and sensing devices requires an understanding of how they work as individuals, as members of teams and communities. HWID approach studies how to understand, conceptualize, and design for the complex and emergent contexts in which information and communication technologies (ICT) and work are entangled. In this paper, through two use cases we illustrate how insights obtained from HWID analysis can be used for the design guidelines of the different interfaces part of the smart university platform.

\footnotetext{
${ }^{1}$ http://www.ebtic.org/pages/the-intelligent-campus
} 


\section{$2 \quad$ Learning Analytics}

Students' interactions with university systems are leaving increasing digital footprints which can be harnessed to understand behaviour and activities of students as well as help them become more effective in their studies and preparation of their career. Learning analytics have used these digital footprints left by students to gain insight on the students' progress and to build a personalised learning environment. However, most of these projects have been looking at the monitoring of the digital environment that the institution offers to the students. Data that is used for these analytics rely on management data, such as student demographics, grades, recruitment figures and the traces left by the students as they use the university IT systems such as virtual learning environment (VLE) or Learning management system (LMS).

Masses of data can be collected from different kinds of student actions, such as solving assignments, taking exams, online social interaction, participating in discussion forums, and extracurricular activities. This data can be used for Learning Analytics to extract valuable information, which might be helpful for lecturers to reflect on their instructional design and management of their courses. Usable Learning Analytics tools for lecturer that support cyclical research activities are still missing in most current VLE or are far from satisfactory [5]. Data mining tools are usually designed for power and the flexibility of the analytics rather than for the simplicity. Most of the current data mining tools are too complex for educators to use and their features go well beyond the scope of what they might require [6] If tracking data is provided in a VLE, it is often incomprehensible, poorly organized, and difficult to follow, because of its tabular format. As a result, only skilled and technically savvy users can utilize it [7]. Many lecturers, using learning analytics are motivated to evaluate their courses and they already have questions related to their teaching in mind.

\section{The Smart University}

Over the past decade, innovation in design and manufacturing throughout the industry has enabled the cost, size, power consumption of sensors and the associated networks to improve dramatically. Consequently, sensor-based systems have been proposed for a broad range of monitoring applications; more recently, these technologies have allowed the integration of the cyber world to physical world and effectively blurring the gap between the two.

The smart university proposed a novel platform that will provide context aware information to students through the integration of learning analytics with data sensed using cyber-physical devices in order to provide a holistic view of the environments that universities offer to students. Additionally, this will augment the traditional learning analytics with data related to the physical environment and allow the investigation of these intelligent buildings and their effect on the learning processes. The platform aims to combine a responsive architectural environment with an intelligent virtual environment in order to offer a truly personalised learning environment. The respon- 
sive architectural buildings will be providing optimal heating, ventilation and lighting based on the requirements of the learning environment (i.e. chemistry lab or ICT lab), the learning models and the behaviour of the occupant of the environment. The behaviour of the occupant (learner or tutor) can be monitored by their interactions with the IT systems as well as some wearable devices. Sensors measuring temperature, humidity, noise and air quality would be used to monitor the behaviour of the building. Figure 1 illustrates the platform that could be used collecting, processing and visualising the data in a smart university. The platform will need to be scalable, data oriented and distributed with a friendly usable interface while, at the same time, being powerful and flexible enough for the repository of data of heterogeneous sources, integration of data sources in real-times, providing real-time exploration and interventions.

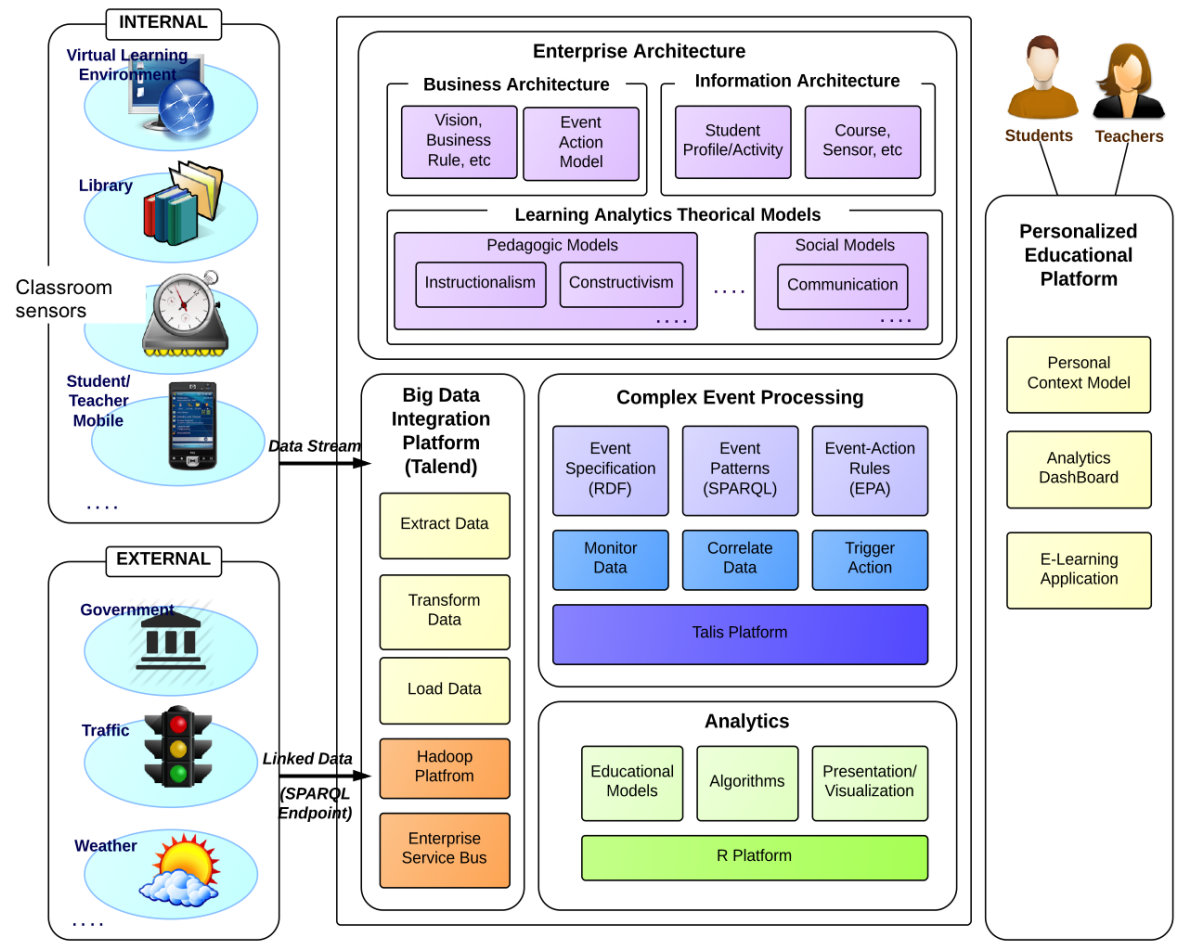

Fig 1. Example of Smart University platform

The platform will need to provide the following capabilities:

- Pre-process data sensed from cyber-physical devices, aggregate sensor data based on pre-determined contexts

- Use data mining and machine learning techniques to identify patterns, trends and anomalies on the general physical environment of university facilities and usage of those facilities. 
- Diagnostics and prognostics capabilities

- Student engagement based on facilities usage

- Lab/classroom/building capacities

- Attendance of events

- Learning analytics

- Integrating influence of intelligent buildings on student learning

- Localised based information useful to students/tutors

- Interventions based on alarms, diagnostics, prognostics of student experience level based on usage of university facilities, student's study load and requirements, etc.

\section{$4 \quad$ Human Work Interaction Design}

Human work analysis is focused on user goals, user requirements, tasks and procedures, human factors, cognitive and physical processes, and contexts (organizational, social, cultural). For instance, Hierarchical Task Analysis [8] and Work Domain Analysis $[9,10]$ are used to study goal-directed tasks and to map the work environmental constraints and opportunities for behaviour. The study of HCI has historically adapted work analysis methods such as hierarchical task analysis to the design of computer artefacts. Ethnographic methods [11] with a sociotechnical perspective have also been used in HCI (e.g.,[12]). These approaches focus on work as end-user actions performed collaboratively with other people in a field setting: the worker activity is seen as a social and organisational experience. In this context, human work analysis and $\mathrm{HCI}$ are interlinked in such as a way to form a distinct field of knowledge, namely HWID.

HWID studies how to understand, conceptualize, and design for the complex and emergent contexts in which information and communication technologies (ICT) and work are entangled. Several aspects influence the way humans work and the work itself. For humans, language, culture, education, skills, knowledge, emotions and cognitive abilities contribute to define the profile of users and their approach to individual and collaborative work. For work, its goals, functions, available tools and content contribute to delineate its characteristics and challenges. In this paper, we illustrate the use of Cognitive Work Analysis (CWA), a well known work analysis technique, to support design considerations for the Smart University system. This technique is driven by a framework that supports and structures the analysis needed when designing a flexible and adaptive system $[9,13]$. The framework focuses on analysing the limitations and constraints on workers behaviour; and mapping these constraints is the design of the system that will support the workers.

The CWA framework comprises five different phases; work domain analysis, control task (or activity) analysis, strategies analysis, social organisation and co-operation analysis, and worker competencies analysis. Using CWA has two distinct advantages. First, CWA is a multi-dimensional analysis that incorporates the physical and the social environment to provide a rich description. Secondly, CWA can be paired with Ecological Interface Design (EID) [14] to generate designs for new in- 
formation systems. EID has shown success in the design of analytic information displays in power plant displays [15]; social systems [16], healthcare decision support [17] and community building [18]. For these reasons, CWA may be a promising approach in cyber physical systems like the smart university.

\section{Applying HWID to Smart University Scenarios: two examples}

In this paper, HWID concepts and tools will be applied to two types of activities in high education domain; exemplifying two aspects of the smart university platform; the learning analytics aspect and cyber-physical devices. The analysis that is discussed in this paper will shape the guidelines of the user interface of the smart university platform.

One of the activities is related to a lecturer using learning analytics to provide support to students when preparing for an exam. The lecturer uses Virtual learning platform (VLE) as the main medium for communicating with the students. Past exams, revision notes and other supporting exercises are uploaded on the VLE. The lecturer, might also initiate a special discussion board for exam support. Here we envisage that the learning analytics will allow the lecturer to monitor the effectiveness of the support that is being provided, helping him/her to adapt the materials accordingly.

The other activity is related to the smart campus; i.e. equipping the campus with cyber-physical devices that help provide responsive environment. An example of such environment is an ICT lab. The lab is equipped with a number of sensors; Students usually take a 2 hours practical session in this ICT lab. Each student has a set of exercises that they have to complete using the computer. The session is typically supported by an academic staff and an assistant; typically a $\mathrm{PhD}$ student.

In this section we present two possible scenarios for the Smart University platform analysed from a HWID perspective. This involves applying CWA and then translating insights from this process into interaction design guidelines for the different interfaces on this platform.

\subsection{Scenario A: supporting exam preparation}

A lecturer, who offers weekly online exercises has the intention to help his/her students to prepare for an exam. But she is not sure if the currently available exercises are helpful enough for this purpose. Therefore, he/she would like to know if those students who practice with her online exercises on a weekly basis are better in the final exam than students who do not use them. A Learning Analytics toolkit could help him/her to do research on this hypothesis by automatically collecting, analyzing, and visualizing the right data in an appropriate way. The smart university platform should allow for interactive configuration in such a way that its users could easily analyze and interpret available data based on individual interests.

We now look at this scenario through the lens of the different phases of CWA. 


\section{Work Domain Analysis:}

Work Domain Analysis (WDA) provides an overview model of the work environment with a view to understanding what kinds of information should be included in the user interface and how this should be presented. The learning analytics toolkit is part of a sociotechnical system whose main goal is maximising learning outcomes and the learning experience for students. The following presents an Abstraction Hierarchy (AH) typically used for WDA [17]. This is made of five levels, which are now described in terms of the learning analytics scenario:

\begin{tabular}{|l|l|}
\hline \multicolumn{2}{|c|}{ WDA: supporting exam preparation } \\
\hline Physical form & $\begin{array}{l}\text { for student (type, program, year of admission, status, performance level); for } \\
\text { learning material (type, date available); for evaluation material (type, date of } \\
\text { evaluation, grades achieved), for lecturer (level, name, availability); for stu- } \\
\text { dent record system (type, data available, dates accessed) }\end{array}$ \\
\hline $\begin{array}{l}\text { Physical } \\
\text { function }\end{array}$ & $\begin{array}{l}\text { Student, VLE, Lecturer, university student record system, material to be } \\
\text { learned, evaluation material }\end{array}$ \\
\hline $\begin{array}{l}\text { Generalized } \\
\text { function }\end{array}$ & $\begin{array}{l}\text { Student accessing material, lecturer creating and uploading new materi- } \\
\text { al, contributing to discussion board, monitoring and evaluation of student's } \\
\text { progress }\end{array}$ \\
\hline $\begin{array}{l}\text { Abstract } \\
\text { function }\end{array}$ & Balance the ratio of evaluation to learning \\
\hline $\begin{array}{l}\text { Functional } \\
\text { Purpose }\end{array}$ & Maximize learning outcomes, Maximize student experience \\
\hline
\end{tabular}

Table 1. Work domain analysis for learning analytics scenario

Since education is a core goal of this scenario, learning needs to be present in the functional purpose and generalized function levels. The scenario indicates that there is a concern that weekly exercises might improve learning, as evaluated through exam results, or might not be helpful. This is why we have chosen to describe at the abstract function level that there must be a balance between evaluation and learning, e.g. you cannot evaluate $100 \%$ of the time, you cannot also never evaluate. The functional purpose is to find the sweet spot where learning outcomes and student experience are maximised at optimum levels.

WDA will allow us to identify the analytics data needed for designing components of the system. For instance, a key goal derived from this WDA is to enable the instructor to move that sweet spot between evaluation and learning to maximize out- 
comes and experience. Those are the drivers, i.e. decisions to be made with the analytic system.

\section{Control Task Analysis:}

This is done to determine what tasks are being carried within the system and under what conditions. In this learning analytics scenario, control task analysis (ConTA), based Rasmussen's decision ladder [18], the analysis would look like in Figure 3. Is there uncertainty and ambiguity on the possible goal state? Quite possibly, if the instructor is following a new evaluation approach for students, she may move into knowledge based behavior [7] trying to figure out what is wrong. Analytics could play a role here. Instructors can then 'define a task', i.e. choose to modify their instruction approach. This implies setting a new 'procedure', more or less exercises in this case, which would then be 'executed'.

\section{Strategies, Social and Worker Competencies:}

This level of analysis can facilitate the discussion of different teaching strategies (traditional, flipped, blended learning). This could also reveal different evaluation strategies (short quick frequent evaluations, longer midterm/final, or project based evaluation).

The identification and description of social competencies could represent values and intentional constraints being conveyed by the institution. It could also consider the culture and cooperation of the students in this. As a worker, the instructor must have competency in teaching, the material being taught, and the use of the smart learning system. Skills, rules and knowledge is the base for all of these [7]. 


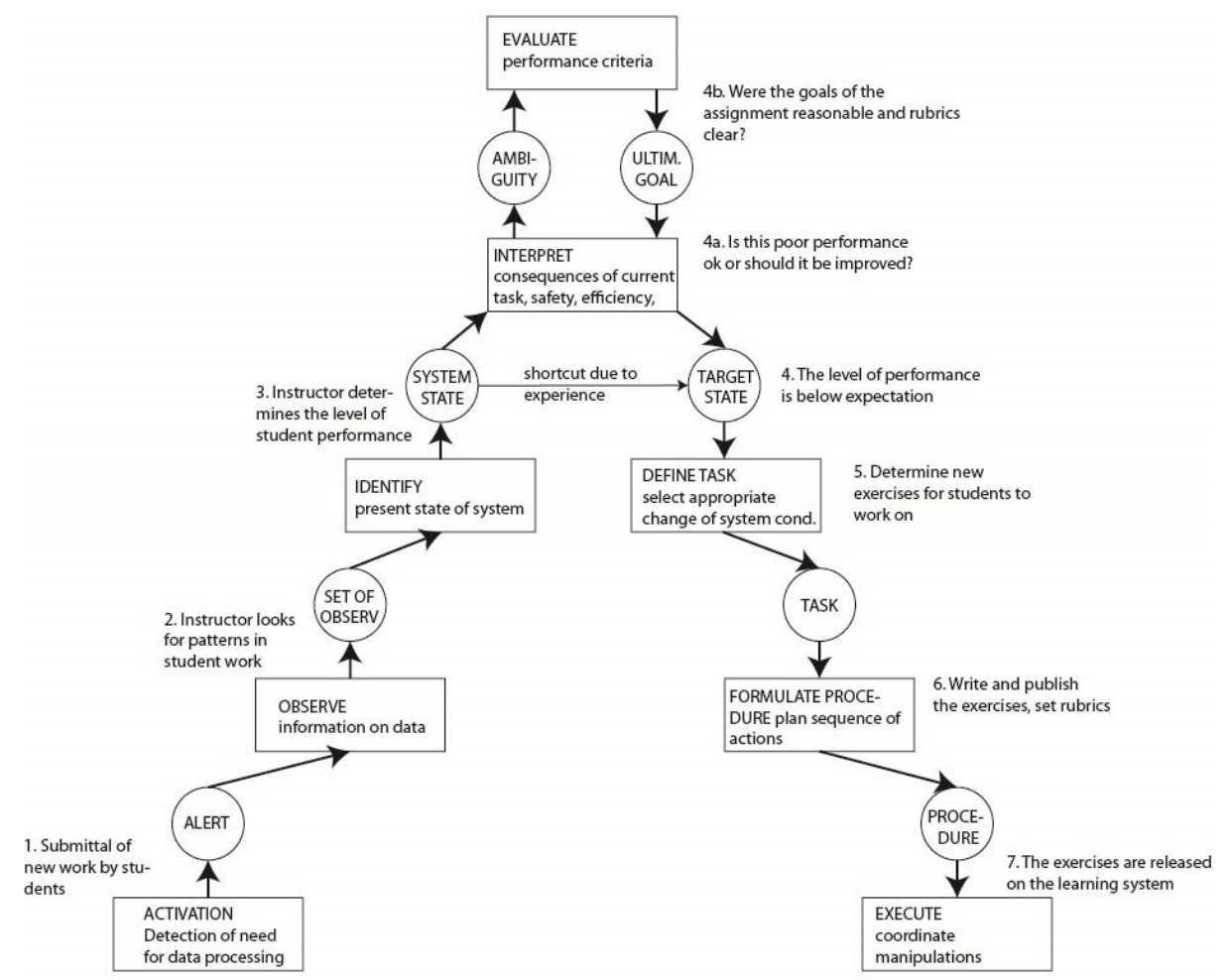

Fig. 3. Decision ladder for learning analytics scenario.

\subsection{Scenario B: monitoring room temperature in the Smart Campus}

In this scenario, the ICT lab at the university is equipped with an number of sensors and a display at the lecturer station with dashboard and message board for information about the room. Once the students have entered the room and started working, the information about the room is updated with an estimate of the number of people in the room and the ideal temperature for the ICT lab activity. The lecturer had a quick look at the dashboard and noticed that the room was empty for the morning and he/she understood that it will take about 5 minutes to get the ideal temperature. He/she also noticed that the noise was higher than what is expected for an ICT session and he/she first closed the windows and the door before asking students to work more quietly.

The students with wearable devices capable of giving ambient temperature readings also noticed that the temperature adjusted to the ideal temperature within 5 minutes of being in the lab.

Work Domain Analysis:

As with the scenario A, we now illustrate a possible WDA for the scenario of controlling temperature in the classroom: 


\begin{tabular}{|l|l|}
\hline \multicolumn{2}{|c|}{ WDA: Monitoring Room Temperature in the Smart Campus } \\
\hline Physical form & $\begin{array}{l}\text { student (type of clothing, course studying ); for ICT lab (size, nb of machine, } \\
\text { nb of windows, ideal climate); sensors(type), for lecturer (level, name); ses- } \\
\text { sion (activity, nb of students, duration), for display(type (dashboard, weara- } \\
\text { ble), data available, messages/alert) }\end{array}$ \\
\hline $\begin{array}{l}\text { Physical } \\
\text { function }\end{array}$ & Student, ICT lab, sensors, snapshot of climate, ICT session, display \\
\hline $\begin{array}{l}\text { Generalized } \\
\text { function }\end{array}$ & $\begin{array}{l}\text { Student attending the ICT session, lecturer receiving messages about the room, } \\
\text { adjusting the room, adjusting own clothing/noise, student receiving personal- } \\
\text { ized message, evaluation process }\end{array}$ \\
\hline $\begin{array}{l}\text { Abstract } \\
\text { function }\end{array}$ & Balance the ratio of climatic comfort to learning \\
\hline $\begin{array}{l}\text { Functional } \\
\text { Purpose }\end{array}$ & Maximize learning outcomes, Maximize student experience \\
\hline
\end{tabular}

Table 2. WDA Monitoring Room Temperature in the Smart Campus (the Smart Campus)

\section{Control Task Analysis:}

This is done to determine what tasks, data, and messages are being processed within the system and under what conditions. In this monitoring ICT lab temperature scenario, inspired in Rasmussen's decision ladder [18] the analysis would look like in Figure 4 . The objective here is to define and implement contextual, multi-sensory inference strategy services that are able to derive contextual information from aggregating different sources data. This will allow us to model user-based energy profiles and user behaviours in the ICT sessions. Based on the contextual models defined and considering the constraints related to comfort, it will be possible to identify diverse energy awareness rendering messages providing adequate feedback on various personalized display (wearables) or the instructor dashboard.

\section{Strategies, Social and Worker Competencies:}

Two strategies are apparent; first, to be energy efficient (i.e. suggestion of taking piece of clothing, opening a window or closing a door) or second, to emphasis on the comfort and make more use of the heating or cooling system. Ultimately, a smart university system will aim to use thermal comfort to change the expectation from largely invisible centralized control of the environment into a more active and respon- 
sive approach. Furthermore, the system will implement a 2-way information exchange between occupants and buildings.

In terms of social competencies, students and staff awareness of and responsibility for environmental issues is variable. How can we facilitate and encourage sharing of thermal comfort strategies and learning from others? For example what are the alternative ways to keep cool or warm, or how to generate reflection on clothing and its role in thermal comfort? As a worker, the instructor must have the competency to understand the correlations between climatic comfort and student performance and make the right type of decisions about the required behavior.

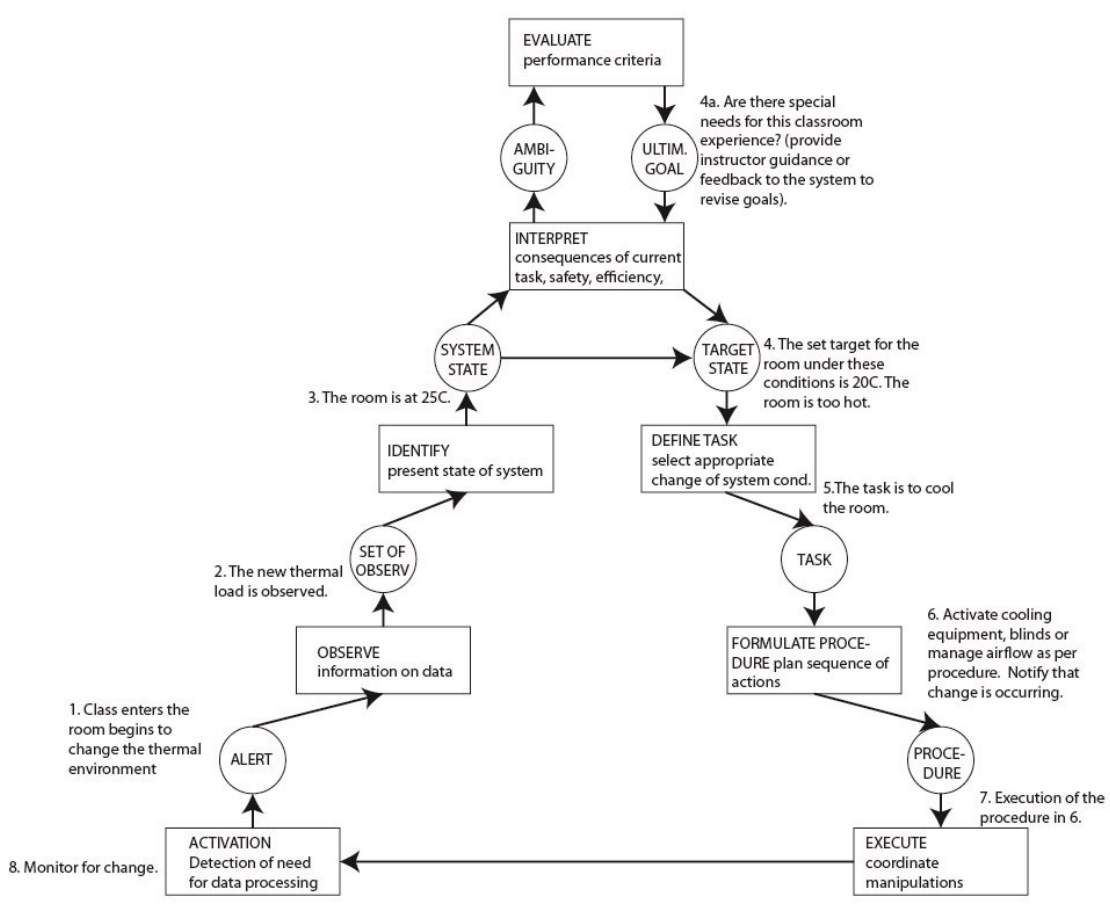

Fig. 4. Monitoring room temperature in the Smart Campus scenario.

\section{CWA Moderated Interface Design}

A Looking at two scenarios through the CWA approach facilitates the decision on which usability and user experience goals that should drive the interaction design of the different interface components of the smart university sociotechnical system. This also applies for the type of user interface design guidelines and levels of representation required at conceptual design level. 
The CWA of the learning analytics scenario clearly points to importance of effectiveness and utility [21] as main usability goals driving the design of the user interface of the lecturer trying to establish the optimum level of exercises that should be set for students to meet learning goals in a satisfactory way.

In terms of design guidelines feedback and mapping become core objectives in the presentation of the student performance data. Good user interface design meeting these goals and principles will support the overall functional purpose of the learning analytics systems, i.e. Maximize learning outcomes, Maximize student experience. Similarly, in the ICT lab monitoring scenario, the effectiveness of the adaptive comfort messages is an essential goal since the underlying objective is to change the students environmental behaviour.

It can be illustrated how specific interface design decisions on relevant guidelines and heuristics can be derived from looking at the WDA and ConTA for both scenarios: Table 3 links key tasks to user behaviour, user interface components, design concepts and design principles and heuristics.

\section{Conclusions}

This paper introduces a proof of concept attempt to illustrate how HWID can be a useful framework in the design of the smart university platform as sociotechnical ecology of information sharing actors and devices. Through the application of CWA to two different scenarios we have identified the nature of work, artefacts and interactions in which smart university users will engage.

The smart university scenarios have been focused on the common functional purpose of maximizing learning outcomes while maximizing the student experience. CWA has enabled an understanding of the different task requirements in each scenario in order to achieve this: in the first scenario on learning analytics, it has been uncovered how finding the right balance between learning and evaluation is a critical goals; on the second scenario on the use of temperature sensors in the smart campus it is clear that the visualization of relations between climatic comfort and learning experience is a critical goal. Looking at these scenarios through ConTA provides an understanding of behaviours according to skills, rules and knowledge in the context of task goals. Identifying the type of behaviour the user is engaged in will provide useful information on cognitive and material elements of the tasks that should be supported. For instance, it is evident to see how in the learning analytics scenario the teacher is likely to be engaged in knowledge based behaviour more often trying to establish the optimum level of exercises for a particular group, while in the smart campus scenario a rule based behaviour is likely to be more frequent as the relation between climatic comfort and student experience will tend to be more stable.

We were then able to illustrate how this analysis of work in these two smart university scenarios can feed the interaction design of user interface components in the different points of interaction with the platform. There will be a need to prioritize different types of usability and user experience goals in terms of the functional purpose and desired goal states in identified in CWA. 


\begin{tabular}{|c|c|c|c|c|}
\hline $\begin{array}{l}\text { General- } \\
\text { ised Func- } \\
\text { tion Task: }\end{array}$ & $\begin{array}{l}\text { Behaviour } \\
\text { Type Re- } \\
\text { quired }\end{array}$ & $\begin{array}{l}\text { User Inter- } \\
\text { face Compo- } \\
\text { nents }\end{array}$ & $\begin{array}{l}\text { Design Con- } \\
\text { cepts }\end{array}$ & $\begin{array}{l}\text { Design Principle and } \\
\text { Heuristic }\end{array}$ \\
\hline $\begin{array}{l}\text { Monitoring } \\
\text { and evalua- } \\
\text { tion of } \\
\text { student's } \\
\text { progress }\end{array}$ & $\begin{array}{l}\text { Skill-based } \\
\text { behaviour }\end{array}$ & $\begin{array}{l}\text { Learning } \\
\text { Analytics } \\
\text { Dashboard: } \\
\text { Messag- } \\
\text { es/alerts }\end{array}$ & $\begin{array}{l}\text { Visualise infor- } \\
\text { mation on stu- } \\
\text { dent perfor- } \\
\text { mance as well } \\
\text { as the level of } \\
\text { instructor sup- } \\
\text { port. }\end{array}$ & $\begin{array}{l}\text { Feedback: lecturer } \\
\text { should receive immedi- } \\
\text { ate, intelligible alert if } \\
\text { performance falls below } \\
\text { expected levels. } \\
\text { Mapping: data visualised } \\
\text { should map naturally to } \\
\text { student's activity record. } \\
\text { Any non-technical user } \\
\text { should be able to under- } \\
\text { stand the student's posi- } \\
\text { tion in relation to her } \\
\text { cohort. }\end{array}$ \\
\hline $\begin{array}{l}\text { Lecturer } \\
\text { creating and } \\
\text { uploading } \\
\text { new materi- } \\
\text { al }\end{array}$ & $\begin{array}{l}\text { Knowledge- } \\
\text { based behav- } \\
\text { iour }\end{array}$ & $\begin{array}{l}\text { VLE content } \\
\text { creation mod- } \\
\text { ule }\end{array}$ & $\begin{array}{l}\text { Supports the } \\
\text { creation and } \\
\text { upload of new } \\
\text { exercises }\end{array}$ & $\begin{array}{l}\text { Visibility: lecturer should } \\
\text { be able to view historical } \\
\text { performance data on } \\
\text { exercises attempted and } \\
\text { overall module perfor- } \\
\text { mance while setting } \\
\text { exercise levels. } \\
\text { User Control and Free- } \\
\text { dom: enable lecturers } \\
\text { maximum control of } \\
\text { creation and uploading of } \\
\text { as many exercises as } \\
\text { required. }\end{array}$ \\
\hline $\begin{array}{l}\text { Lecturer } \\
\text { monitors } \\
\text { temperature } \\
\text { and noise } \\
\text { levels }\end{array}$ & $\begin{array}{l}\text { Rule-based } \\
\text { behaviour }\end{array}$ & $\begin{array}{l}\text { Temperature } \\
\text { and noise } \\
\text { charts in } \\
\text { classroom } \\
\text { based control } \\
\text { panel }\end{array}$ & $\begin{array}{l}\text { Visualising the } \\
\text { required infor- } \\
\text { mation quickly } \\
\text { and in a non- } \\
\text { disruptive form }\end{array}$ & $\begin{array}{l}\text { Throughput: monitoring } \\
\text { temperature and noise } \\
\text { levels should not disrupt } \\
\text { the core teaching tasks } \\
\text { and should be done as } \\
\text { quickly as possible. } \\
\text { Feedback: lecturer } \\
\text { should receive clear } \\
\text { indication of temperature } \\
\text { and noise levels, with } \\
\text { clear indication of ac- } \\
\text { ceptable thresholds. }\end{array}$ \\
\hline
\end{tabular}

Table 1. Mapping CWA to choose relevant user interface design concepts, principles and heuristics. 
Even in the present examples, it is easy to predict that supporting the instructor with analytics on student performance would be a more extensive design challenge than providing monitoring of the thermal conditions of the classroom. This also has implications on data visibility, information accessibility, and information architecture. In the case of monitoring student performance, the instructor needs a deeper architecture, more data accessibility and more control latitude to develop the view he or she may want. In contrast, the thermal comfort situation may require quite straightforward information display and limited control to the instructor and students.

HWID models also provide considerations for nation, geographic, cultural, social and organizational factors shaping the activities being supported through design [22]. The smart university does not escape these considerations and any of the models and design principles and heuristics shaping the interactive points in these platforms will have to be moderated by them. For instance, Northern European universities will have challenges for design very different from those in the Southern Europe due to cultural, political and climatic factors.

In summary, we have illustrated a case for HWID in the context of the design of the smart university. Work analysis and interaction design can be integrated to support important design decisions affecting the ecology of devices and information repositories in the smart university with a clear focus on its users, their contexts and interactions.

\section{$8 \quad$ References}

1. Clemmensen, T., Campos, P.F., Katre, D.S., Abdelnour-Nocera, J., Lopes, A., Orngreen, R., Minocha, S.: CHI 2013 human work interaction design (HWID) SIG: past history and future challenges. CHI'13 Extended Abstracts on Human Factors in Computing Systems. pp. 2537-2540. ACM (2013).

2. Sauer. C., Oussena S., (2014) Approaches to the Use of Sensor Data to Improve Classroom Experience, eChallenges e-2014 Conference, Belfast

3. Oussena, Samia, Hyensook Kim, and Tony Clark. "Exploiting Student Intervention System Using Data Mining." IMMM 2011, The First International Conference on Advances in Information Mining and Management. 2011

4. Lei, C.-U., Man, K.L., Liang, H.-N., Lim, E.G., Wan, K.: Building an Intelligent Laboratory Environment via a Cyber-Physical System. International Journal of Distributed Sensor Networks. 2013, 1-9 (2013).

5. Hijon, R., Velázquez, Á.: E-learning platforms analysis and development of students tracking functionality. World Conference on Educational Multimedia, Hypermedia and Telecommunications. pp. 2823-2828 (2006).

6. Romero, C., Ventura, S., García, E.: Data mining in course management systems: Moodle case study and tutorial. Computers \& Education. 51, 368-384 (2008).

7. Mazza, R., Dimitrova, V.: CourseVis: A graphical student monitoring tool for supporting instructors in web-based distance courses. International Journal of Human-Computer Studies. 65, 125-139 (2007).

8. Annett, J., Duncan, K.D.: Task analysis and training design. (1967).

9. Vicente, K.J.: Cognitive work analysis: Toward safe, productive, and healthy computerbased work. CRC Press (1999). 
10. Salmon, P., Jenkins, D., Stanton, N., Walker, G.: Hierarchical task analysis vs. cognitive work analysis: comparison of theory, methodology and contribution to system design. Theoretical Issues in Ergonomics Science. 11, 504-531 (2010).

11. Button, G., Sharrock, W.: Studies of Work and the Workplace in HCI: Concepts and Techniques. Synthesis Lectures on Human-Centered Informatics. 2, 1-96 (2009).

12. Abdelnour-Nocera, J., Dunckley, L., Sharp, H.: An approach to the evaluation of usefulness as a social construct using technological frames. International Journal of Human-Computer Interaction. 22, 153-172 (2007).

13. Lintern, G.: The Foundations and Pragmatics of Cognitive Work Analysis: A systematic approach to design of large-scale information systems. Retrieved March. 1, 2009 (2009).

14. Hajdukiewicz, J., Burns, C.: Strategies for bridging the gap between analysis and design for ecological interface design. Proceedings of the Human Factors and Ergonomics Society Annual Meeting. pp. 479-483. SAGE Publications (2004).

15. Burns, C.M., Skraaning, G., Jamieson, G.A., Lau, N., Kwok, J., Welch, R., Andresen, G.: Evaluation of ecological interface design for nuclear process control: situation awareness effects. Human Factors: The Journal of the Human Factors and Ergonomics Society. 50, 663679 (2008).

16. Hajdukiewicz, J.R., Burns, C.M., Vicente, K.J., Eggleston, R.G.: Work domain analysis for intentional systems. Proceedings of the Human Factors and Ergonomics Society Annual Meeting. pp. 333-337. SAGE Publications (1999).

17. Burns, C.M., Enomoto, Y., Momtahan, K.: A cognitive work analysis of cardiac care nurses performing teletriage. Applications of cognitive work analysis. 149-174 (2008).

18. Euerby, A., Burns, C.M.: Improving Social Connection Through a Communities of Practice-Inspired Cognitive Work Analysis Approach. Human Factors: The Journal of the Human Factors and Ergonomics Society. 0018720813494410 (2013).

19. Rasmussen, J.: The role of hierarchical knowledge representation in decisionmaking and system management. Systems, Man and Cybernetics, IEEE Transactions on. 234-243 (1985).

20. Rasmussen, J., Pejtersen, A.M., Goodstein, L.P.: Cognitive systems engineering. Wiley (1994).

21. Rogers, Y., Sharp, H., Preece, J.: Interaction design: beyond human-computer interaction. John Wiley \& Sons (2011).

22. Katre, D., Campos, P., Clemmensen, T., Orngreen, R., Pejtersen, A.M.: Human Work Interaction Design for e-Government and Public Information Systems. In: Campos, P., Graham, N., Jorge, J., Nunes, N., Palanque, P., and Winckler, M. (eds.) Human-Computer Interaction - INTERACT 2011. pp. 730-731. Springer Berlin Heidelberg, Berlin, Heidelberg (2011). 